Case report:
cobblestone

Department of
Dermatology,
Venereology and
Leprology
Postgraduate Institute
of Medical Education
and Research,
Chandigarh, India
S Gupta
B Kumar

Department of Dermatology and STD, Postgraduate Institute of Medical Sciences, Rohtak, Haryana, India S Gupta

V K Jain

Correspondence to: Dr Bhushan Kumar, Department of Dermatology, Venereology and Leprology, PGIMER, Chandigarh - 160 012 , India

kumarbhushan@hotmail.com

Accepted for publication 7 June 2000

\title{
A "stone" in the vulva
}

\author{
Somesh Gupta, Sanjeev Gupta, Vijay Kumar Jain, Bhushan Kumar
}

A 62 year old, married, multiparous woman (menopausal for past 18 years) presented with the complaint of having a hard nodule (which she described as a "stone") in her genitalia. About 12 years earlier she developed a small swelling which was soft and painless initially, but later became hard and tender, causing discomfort during sexual intercourse. There was no history of ulceration, bleeding, or discharge from the swelling. On examination, a solitary vulvar tumour $2 \times 1 \mathrm{~cm}$ in size was seen inside a thick walled sac with a narrow opening on the skin surface of upper third of the right labia minora (fig 1A). On palpation, the mass was "stony" hard in consistency and was tender on deep pressure. It was freely mobile beneath the skin. When an incision was performed to widen the opening, the tumour came out easily (fig 1B). The histopathological examination of the excised mass revealed laminated calcified keratinous material with attenuated stratified squamous epithelium lining, suggestive of calcified epidermoid cyst.

The epidermoid cysts are intradermal keratinising cysts lined by squamous epithelium. The common sites of involvement are face, trunk, neck, extremities, and scalp. ${ }^{1}$ The vulva is a rare site. ${ }^{1}$

Though histopathologically similar, the epidermoid cysts of the hairy and non-hairy areas differ in their pathogenesis. It has been
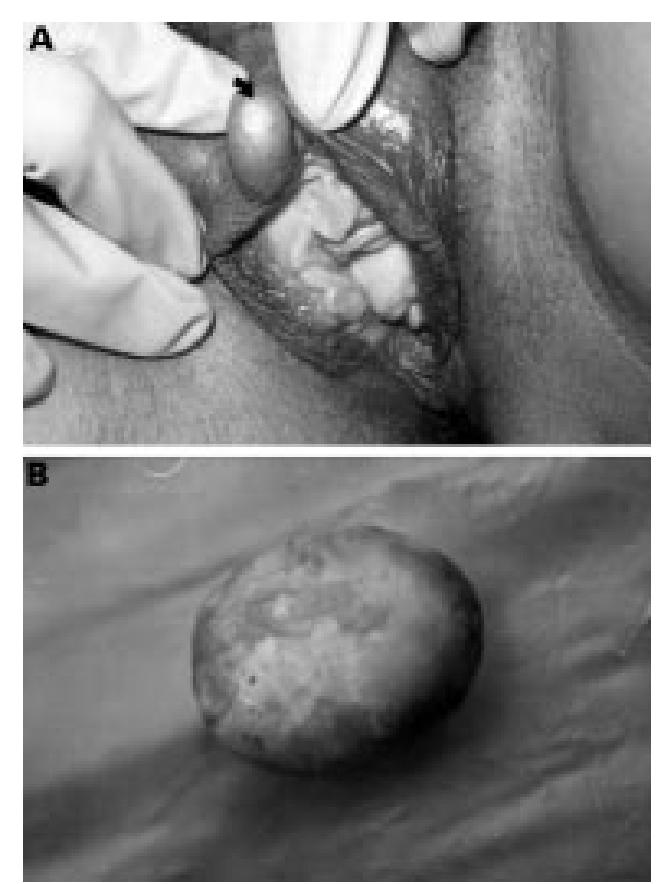

Figure 1 (A) A hard, calcified epidermoid cyst inside a sac, visible through a narrow opening in the skin of labia minora (arrow). (B) The excised calcified cyst. suggested that the epidermoid cysts on the acne prone areas such as the face, neck, and upper trunk result from the damage to the pilosebaceous unit. ${ }^{2}$ On the other hand, on the palms, soles, and other body areas they may result from penetrating trauma with resultant implantation of squamous epithelium into the dermis. $^{2}$ On the vulva, these cysts may result from the burial of fragments of the skin after the trauma of childbirth or episiotomy. ${ }^{3}$ Women of some ethnic origins, who undergo ritual circumcision during infancy, may develop epidermoid cysts of the vulva more frequently because of implantation of skin fragments during this crude procedure. ${ }^{4}$

Various complications related to epidermoid cysts are due to the effect of trauma, which may rupture the wall with release of keratinous debris into the surrounding dermis leading to a violent inflammatory reaction of the foreign body type. ${ }^{5}$ Less commonly, infection and haematoma and, rarely, carcinomatous changes may occur in neglected cysts. Dystrophic calcinosis has frequently been reported in the epidermoid cysts of the scrotum. ${ }^{6}$ A literature search, however, failed to reveal a report of similar calcification in the vulvar epidermoid cysts. Pain, discomfort, or rupture of the vulvar epidermoid cyst during sexual intercourse or vaginal delivery probably forces patients to seek medical attention before the process of calcification begins. The epidermoid cysts on the scrotum are often symptomless and patient and/or treating physician may ignore them for years. ${ }^{6}$ In spite of the presence of mild symptoms, our patient neglected the cyst for many years resulting in calcification. We presume that repeated friction produced by the hard calcified nodule caused fibrosis of the surrounding tissue. Later, separation of nodule from the surrounding fibrous tissue, and finally a breach in the continuity of the overlying mucosa led to an appearance of a "hard ball" inside a narrow mouthed "earthen pot."

Contributors: Somesh Gupta was involved in the surgical management of the patient and planning and execution of the manuscript; Sanjeev Gupta took part in the clinical study and literature search; Vijay Kumar Jain took part in the clinical study; Bhushan Kumar in planning and execution of the manuscript.

1 Sachdeva HS, Narang R. Sebaceous cyst vulva. A case report. Am Surg 1968;34:461-2.

2 McGibbon DH, Mckee PH. Tumors of the epidermal appendages. In: McKee HP, ed. Pathology of the skin. Philadelphia: JB Lippincott, 1989:15.3.

3 Hillard PA. Benign diseases of the female reproductive tract. In: Berkek JS, Adashi EY, Hillord PA, eds. Novak's gynecology. Baltimore: Williams and Wilkins, 1996:331-97.

4 Onuigbo WIB. Vulval epidermoid cysts in Igbos of Nigeria. Arch Dermatol 1976;112:1405-6.

5 Arizpe SR, Condiani JO. Giant epidermoid cyst: clinical Arizpe SR, Condiani JO. Giant epidermoid cyst: clinical
aspect and surgical management. $\mathcal{F}$ Dermatol Surg Oncol aspect and surgica

6 Akosa AB, Gilliland EA, Ali MH, et al. Idiopathic scrotal calcinosis: a possible aetiology reaffirmed. Br f Plast Surg 1989;42:324-7. 